\title{
LOS CÉSARES DE LA PATAGONIA, ¿OTRA FUENTE INDÍGENA PARA LA LEYENDA O UNA HASTA AHORA DESCONOCIDA CREACIÓN DEL IMAGINARIO AÓNIKENK?
}

MATEO MARTINIC B.

\section{RESUMEN}

Se entregan antecedentes inéditos acerca de algunas creencias que nutrieron la fantasía de los aónikenk, que guardan semejanzas con la afamada leyenda de la Ciudad Encantada de la Patagonia, lo que permite hacer algunas consideraciones en su respecto y postular una doble hipótesis explicativa: ser otra fuente indígena para el mito legendario, o bien una creación del imaginario de los cazadores australes.

PALABRAS CLAVES: Leyenda de los Césares, Patagonia, Ciudad Encantada o de los Césares, fantasías indígenas.

\section{THE CESARES OF PATAGONIA. ANOTHER INDIGENORES SOURCE FOR LEGEND OR AND UNKNOWN CREATION OF THE AONIKENK IMAGINARY?}

\begin{abstract}
Unknown information about some beliefs that feed aonikenk fantasy is given. They are similar to the famous legend of the Patagonian Enchanted City. This allows doing some related considerations and postulating a double hypothesis as explanation: that these are another indigenous source for the mythic legend, or an imaginative creation of the southernmost hunters of Patagonia.
\end{abstract}

KEY WORDS: Cesar legend, Patagonia, Enchanted City or Cesar's City, indigenous fantasies.

\section{INTRODUCCIÓN}

Al promediar el siglo XVI comenzó a esparcirse entre los españoles que se encontraban empeñados en la conquista de Chile y Río de la Plata, un rumor que se refería a una misteriosa población que se situaba, según parecía, en las faldas orientales de los Andes, en un indeterminado lugar ubicado aproximadamente hacia los $35^{\circ}$ ó $36^{\circ}$ de latitud austral. Harto vagas y confusas al principio, las noticias poco a poco fueron confluyendo en tres vertientes: una, que daba cuenta de una rica ciudad fundada por gente indígena de calidad huida del Perú tras la conquista española, que había llevado

Profesor Emérito, Universidad de Magallanes. Centro de Estudios del Hombre Austral, Instituto de la Patagonia. Dirección electrónica: gabriel.bahamonde@umag.cl 
consigo cantidad inconmensurable de oro, plata y piedras preciosas; otra, que se trataba de un poblado en el que habitaba gente riquísima y que había sido descubierto durante una excursión practicada por un cierto Francisco César, capitán español que había integrado la expedición al río de la Plata comandada por Sebastián Caboto; y, por fin, una tercera que fincaba el origen de la creencia en un grupo de españoles capitaneados por Sebastián de Argüello, que se habían salvado del naufragio en el estrecho de Magallanes de una nave que formaba parte de la expedición de Francisco de Camargo (1540), quienes habrían marchado hasta las montañas andinas, estableciéndose junto a un lago, en convivencia pacífica con los indígenas, algunas de cuyas mujeres habrían tomado como esposas. Esta vertiente informativa hubo de adquirir más verosimilitud una vez que en 1563 arribaron a Concepción unos tales Pedro de Oviedo y Antonio de Cobos, ambos españoles, y declararon ante el Licenciado Julián Gutiérrez de Altamirano, Teniente General del Reino de Chile, que eran sobrevivientes del naufragio de marras y que procedían de la población formada con posterioridad, de la que habían huido tras verse comprometidos en un homicidio. La noticia no demoró en difundirse y ser tenida por verídica. Esta versión fue la que acabó por consolidarse y predominar en la memoria colectiva haciendo que las otras dos perdieran importancia y acabaran olvidadas.

Así surgió y se desarrolló la leyenda de la Ciudad de los Césares o de los Césares de la Patagonia, o Ciudad Encantada de la Patagonia, diferentes formas en que fue mencionada, a la que sobre la base del presunto fundamento original no demoraron en agregarse atributos maravillosos tales como la abundancia de riquezas y bienes de toda clase, y la larga vida o aun la inmortalidad de sus habitantes, amén de otras bondades igualmente sorprendentes que contribuyeron a cimentar la fama y la sostenida persistencia del mito a lo largo del resto del siglo XVI y por los otros dos siguientes, inclusive con algún eco tardío durante el siglo XIX. Todo ello fue causa suficiente para justificar numerosas expediciones y propuestas de búsqueda, primeramente por los archipiélagos del sur de Chiloé y la costa firme occidental de la Patagonia, y, hacia el tercio final del siglo XVII, por diferentes zonas de la banda oriental andina al sur del lago Nahuelhuapi, por cierto todas infructuosas.
El mito de la Ciudad Encantada de la Patagonia o de los Césares motivó desde temprana época el surgimiento de una literatura especializada, que se ocupó de la materia, lo que basta para calificar el interés sostenido de diferentes autores a lo largo del tiempo. Así se dispone de una bibliografía nutrida y variada, en la que se ha abordado el asunto desde sus diferentes orígenes hasta los resultados de tantos empeños conocidos por dar con la inhallable población cesárea.

Mencionando entre los primeros autores a los historiadores jesuitas PP. Alonso de Ovalle, Miguel de Olivares y Diego de Rosales que recogieron las noticias primigenias del mito y las publicaron durante los siglos XVII y XVIII, deben señalarse entre los más importantes a Pedro de Angelis que se ocupó del asunto, como recopilador, incluyéndolo en el primer volumen de su Colección de Obras y Documentos relativos a la Historia Argentina (Buenos Aires 1836-37, reeditado en 2005 bajo el título de La Ciudad Encantada de la Patagonia. La leyenda de los Césares por Ediciones Continente); a Ricardo Latcham, con su trabajo "La Leyenda de los Césares. Sus orígenes y evolución" (Revista Chilena de Historia y Geografía, volumen IX, Santiago 1920); a los historiadores Enrique de Gandía, autor de La Ciudad Encantada de los Césares (Buenos Aires, 1933) y Ernesto Morales, que publicó La Ciudad Encantada de la Patagonia (Buenos Aires, 1944); hasta llegar en época más reciente a los académicos Patricio Estellé y Ricardo Couyoudmjian con sus bien logrados estudios "La Ciudad de los Césares: origen y evolución de una leyenda (1526-1880)" (Historia $\mathrm{N}^{\circ} 7$, Santiago 1968) y (sólo el último) "La leyenda de los Césares" (Historia $\mathrm{N}^{\circ} 10$, Santiago, 1971), y al estudioso uruguayo Fernando Ainsa, autor de un bien elaborado e interesante artículo, "Una utopía necesaria: la Ciudad de los Césares", publicado en dos ediciones dominicales del diario La Nación de Buenos Aires (15 y 22 de enero de 1989); para concluir con la mención a Carlos Vega Delgado y Carlos Vega Cacabelos que últimamente han publicado el libro Develando el misterio de la Ciudad de los Césares (Fondart, Punta Arenas 2006), recomendable como texto de consulta completo sobre la materia. Este listado selectivo expresa la vigencia de un interés tres veces secular referido a la leyenda, sin duda la de más prolongada vigencia en el imaginario popular americano. 
No es nuestro propósito ocuparnos del tema en sí, ya suficiente y acabadamente abordado por tantos autores precedentes a los que nos remitimos para los efectos de una debida información, sino en tanto que el mismo permite contextualizar algunos antecedentes de origen indígena hasta ahora desconocidos que guardan alguna semejanza con contenidos del mito y que tanto podrían conformar otra fuente aborigen para la leyenda, o, quizá, si no es así, una novedosa creación del imaginario aónikenk, con sólo apariencias de similitud con el mito tradicional, pero definitivamente diferente.

\section{ANTECEDENTES Y CONSIDERACIONES EXPLICATIVAS}

Años atrás, mientras revisábamos ediciones antiguas del diario El Magallanes de Punta Arenas en busca de información sobre una materia que por entonces nos interesaba, encontramos en la edición correspondiente al día 22 de febrero de 1929 un artículo titulado "Historia de una historia" y que hacía referencia al antiguo jefe aónikenk Papón, con noticias sobre el tiempo final de su existencia hasta su fallecimiento en Punta Arenas durante el invierno de $1887^{1}$. De modo particular se mencionaba que en su pobreza final el único bien que le quedaba era una boleadora que, según se afirmaba, al tiempo de venderla en tres pesos fuertes de la época había resultado no ser de bronce, como parecía de primera, sino de oro puro, lo que motivó la curiosidad del comprador que insistió en averiguar dónde había obtenido Papón el valioso trozo de mineral con el

1 Papón era un personaje bien conocido en el reducido vecindario de Punta Arenas allá por los años de 1870 y 1880. Había sucedido a Casimiro Biguá en la jefatura de los indígenas que deambulaban por la Patagonia austral, de preferencia entre el estrecho de Magallanes y el río Santa Cruz hacia 1874. Supo ganarse la simpatía del Gobernador de Magallanes Diego Dublé Almeida, quien para destacarlo le dio el título de "Subdelegado de la Patagonia". Papón fue conocido y tratado por casi todos los exploradores de ese tiempo, y como todos los indígenas de entonces se aficionó a la bebida y acabó por ser un consumidor compulsivo. Así, no pudo escapar al triste sino de sus paisanos, muriendo pobre y virtualmente abandonado. Para mayor información sugerimos ver nuestro libro Los Aónikenk. Historia y Cultura (Ediciones de la Universidad de Magallanes, Punta Arenas, 1995). No obstante lo consignado, cabe señalar que el deceso de Papón ocurrió después de 1892, época en que el explorador Ramón Lista viajó con él hasta Última Esperanza. que se había fabricado la pieza. Fue entonces que el indio contó una sorprendente historia que, de algún modo, llegó a conocimiento de un tal señor "R", y de éste, después, al autor del artículo de marras. Como este escrito, sin indicación de autoría, indicaba que continuaría en una próxima edición, revisamos los días siguientes y en la edición del 7 de marzo encontramos la segunda parte, ahora firmada por las iniciales "C.S.O.". En ésta el autor manifestaba que el jefe aónikenk había contado, con señas y con palabras, la existencia de una ciudad aplastada por las lavas volcánicas de muy viejas erupciones. Además, erupciones recientes cubrían por completo los vestigios que hasta poco tiempo antes, marcaban señales evidentes de una ciudad sepultada. En el sitio indicado como planta de una ciudad, había el cacique Papón recogido el pedazo de oro usado para fabricar la boleadora.

Esta es, a grandes rasgos, la historia que oímos al señor R., omitiendo de ella toda la fantasía contada por el Cacique, por no tener valor histórico. Los gualichos, los brujos y duendes que vio Papón por aquellos lugares, es pura fantasía, material de comedia o de novelistas de bufete.

Pero lo que no es fantasía ni material de novelista, es el hecho comprobado de haber allá en la comarca que señalaba Papón, un sitio que fue plantado con árboles frutales, y que son muchos los que han recogido frutas petrificadas ${ }^{2}$.

La noticia, no obstante que curiosa por demás, no mereció de momento ni durante mucho tiempo nuestra preocupación y sólo tomamos nota de las fechas en que fue publicada, olvidándonos del asunto. Corrió el tiempo hasta 1999 época en la que casualmente se encontró en el Archivo Nacional, un manuscrito titulado "Observaciones meteorológicas en 1844-49" que, más allá de lo que esa denominación sugería, contenía interesantísimas descripciones etnográficas recogidas por Santiago Dunne, secretario de la Gobernación de la Colonia de Magallanes durante el mismo lapso, y que fue considerado de tal importancia que mereció una publicación especial ${ }^{3}$. Pues bien, entre las noticias

2 Edición indicada. Lo destacado es nuestro.

3 Véase nuestro artículo "Informaciones etnográficas extraídas del diario inédito de Santiago Dunne, secretario de la Gobernación de Magallanes (1845)" (Anales del Instituto de la Patagonia, Serie Ciencias Humanas, volumen 28, Punta Arenas 2000). 
de aquel carácter se encontraban las proporcionadas por Santos Centurión, un criollo aindiado que habitaba con los aónikenk, que daban cuenta de avistamientos de unas casas de piedra habitadas por unos enanos peludos, especie de duendes, llamados chélep, realizados durante los viajes de los indígenas por sectores de la precordillera oriental de la Patagonia, y sobre lo que se abunda más adelante. Luego de su lectura, advertimos que había o podía haber alguna relación con los dichos de Papón, sin embargo de lo cual el asunto no concitó de manera especial nuestra preocupación.

Por fin, encontrándose en desarrollo en noviembre de 2005 en Puerto Natales el V Congreso de Historia Regional, uno de los participantes, el sociólogo Ramón Arriagada, dio lectura a su ponencia referida al hallazgo de escritos inéditos de Arthur Button, un inmigrante británico arribado a Última Esperanza en 1905, territorio en el que vivió hasta su muerte pasada la mitad del siglo XX. Estos documentos -cuadernos- habían sido escritos en su vejez, hacia 1951, y habían permanecido en poder de su hija Leslie, habitante de Puerto Prat hasta su fallecimiento en 1956. En ellos Button hacía recuerdo de diferentes asuntos e incidencias, entre otros de los ocurridos a principios del siglo desde su salida de Inglaterra hasta su llegada a Última Esperanza, distrito en el que por entonces abundaba la gente de su nacionalidad, trabajando principalmente como ovejeros en las estancias ganaderas allí establecidas.

Ahora bien, uno de tales recuerdos se refiere a conversaciones que Button tuvo con sus paisanos al tiempo de su llegada y, respecto de lo que interesa, escribió lo siguiente: Los trabajadores de la compañía ganadera 4 hablaban de lo que había sucedido en el pasado. Todos tenían diferentes versiones acerca de varios temas: desde el descubrimiento del Mylodón y la supuesta existencia de algunos animales en las montañas. Una expedición se encontraba entonces buscando el lugar donde habitaban (o se

4 Referencia a la Sociedad Explotadora de Tierra del Fuego, entidad que en 1905 había rematado la mayor parte de las tierras fiscales de uso pastoril en el distrito de Ultima Esperanza, y que había formado sobre su base varios grandes establecimientos de crianza ovina, entre ellos las estancias "Cerro Castillo" (la principal) y "Cerro Guido" (Véase del autor el libro Última Esperanza en el tiempo, Ediciones de la Universidad de Magallanes, Punta Arenas 1985 y 2000). extinguieron $)^{5}$. Se dijo que una tribu de indios que vivían en las montañas se encerró en un valle que era como el paraíso. Nadie podía salir ni entrar. Quizá las historias de Allan Quatermain o Rob Roy les habían lavado el cerebro ${ }^{6}$, ya que desde un punto elevado de la montaña aseguraban ver a los indios trabajando, cosechando maíz con animales tan grandes como milodones, con el maíz casi cubriéndolos por completo. No es necesario decir que muchos creían este cuento ${ }^{7}$.

Oír lo transcrito y relacionarlo de inmediato con las noticias del antiguo artículo periodístico y con el contenido del manuscrito de Dunne fue algo instantáneo y más allá de atribuir el cuento a la invención de Button, cavilé que bien considerado el asunto podía encontrarse una posible ligazón entre unas y otras informaciones. Desde luego, cabe señalar que, de ser verídica en cuanto a su fuente la relación, de lo que no nos cupo ni nos cabe duda alguna, la misma no podía haber sido otra que los indígenas aónikenk del grupo dirigido por Francisco Blanco, y que entre los años de 1890 y 1905 había habitado de manera recurrente en el valle medio del río Vizcachas, en la zona interior de Última Esperanza. En efecto, hay varios antecedentes comprobados que tanto dan fe de tal presencia, como del amistoso trato entre los aborígenes y los foráneos que habían llegado para establecerse como colonos o a trabajar como ovejeros. De modo que, si los informantes británicos de Button habían conocido efectivamente indios aónikenk (patagones o tehuelches), éstos no pudieron haber sido otros que los del grupo del valle Vizcachas.

5 Referencia a la expedición organizada por el diario The Dayly News de Londres y encomendada al periodista Hesketh Prichard, con el encargo de encontrar un milodón vivo en la Patagonia (1901). El origen de esta creencia estaba en el hallazgo ocurrido en una caverna próxima al fiordo Eberhard (Última Esperanza) en 1895, conformado por restos óseos de aquel animal extinto y un trozo de piel con apariencia de frescura que parecía datar de tiempo reciente. De allí derivó la creencia científica de la posible supervivencia del animal y la expedición a la que se hace mención. Por supuesto que Prichard no tuvo éxito en su búsqueda. Para mayor información véase de este autor el libro En el corazón de la Patagonia (Zagier \& Urruty Publications, Buenos Aires 2003).

6 Referencia a leyendas populares en Inglaterra y Escocia.

7 Ramón Arriagada, "Arthur Button: un sorprendente hallazgo" (Actas del V Congreso de Historia de Magallanes, Ediciones de la Universidad de Magallanes, Punta Arenas 2006). 
Pero, en especial, lo relatado por el inglés nos recordó una referencia que habíamos conocido igualmente años atrás cuando investigábamos sobre las primeras exploraciones en Última Esperanza. Encontramos entonces una relación hecha por el explorador argentino Ramón Lista en 1890, una mención a la sierra basáltica de Cahuerne, así nombrada por los Tehuelches, que creen que en ella habitan espíritus maléficos y monstruosos cuadrúpedos, los que, una vez, según la tradición, devoraron una familia entera de indios que viajaban á pie hacia la costa del mar, de regreso de Charre, nombre tzoneca del lago Argentino ${ }^{8}$. El explorador entregaba en seguida una caracterización geológica de tan llamativa formación orográfica.

Así entonces, la aparente coincidencia de las informaciones -en cuanto las mismas no obstante su fantasía mostraban poseer algunos elementos comunes-, nos llevó a interesarnos en la materia, aunque sin adelantar de modo satisfactorio alguna conclusión. Pero, cuando otra vez la casualidad puso en nuestras manos un nuevo antecedente, esto es, el "Memorando referido a los Patagones" sobre el que se trata por separado", decidimos ocuparnos de la materia. En efecto, tras la lectura del último documento concluimos en que había, como en todo producto aparente de la fantasía, algún fundamento, esto es, el vestigio de una antigua creencia que pudo haber alimentado la imaginación de los ya extinguidos aónikenk, fruto a su vez de las que pudieron ser sus interpretaciones acerca de fenómenos y hechos naturales que conocieron durante sus incontables trashumancias de otrora a lo largo y ancho de la Patagonia oriental, en particular sobre la zona de la precordillera, por tantas razones atractiva antaño y ogaño. De esa manera, acabamos por plantearnos algunas hipótesis, en cuanto dice con la posibilidad de aceptar que en el

8 Anales de la Sociedad Científica Argentina, tomo XL, Buenos Aires 1896, pág. 22. La referencia geográfica corresponde a la sierra conocida desde esa misma época con el nombre de Baguales, accidente orográfico que se desprende perpendicularmente hacia el este desde la cordillera de los Andes, y que separa las hoyas del lago Argentino hacia el norte y del complejo lacustre situado en torno al macizo del Paine, hacia el sur. Esta sierra en su parte oriental está conformada por llamativas formas basálticas.

9 Véase en este mismo número el artículo "Documentos inéditos para la historia de Magallanes. Memorando referido a los Patagones", págs. 159-164. mito de los Césares de la Patagonia, de tanta y tan prolongada difusión y vigencia temporal, más allá de coincidencias y semejanzas de contenido entre el mismo y los antecedentes que se han colacionado, pudo haber otra fuente indígena, específicamente fruto del imaginario colectivo aónikenk.

Hasta ahora, que se sepa, ninguno de los que se han ocupado de la materia, ha mencionado la posibilidad de una fuente indígena meridional para la leyenda cesárea, de allí que interesa ocuparse del asunto y esforzarse por encontrar una explicación valedera que puede surgir y que se expone en este trabajo.

En la consideración del asunto, lo primero que parece que corresponde es correlacionar los antecedentes, esto es, ver cuáles y cuántos elementos caracterizadores, entendidos en sentido amplio, son comunes y compartidos por las diferentes relaciones. Para el caso denominamos las fuentes según su orden de mención: 1 (Papón), 2 (Centurión), 3 (Button) y 4 (Lista), dejando de lado, por ahora, para una consideración complementaria, la mención a la quinta fuente, el memorando. De este modo hemos confeccionado el siguiente cuadro:

\begin{tabular}{lcccc}
\hline \multicolumn{5}{c}{ Fuentes } \\
\hline $\begin{array}{l}\text { Elementos } \\
\text { caracterizadores }\end{array}$ & $\begin{array}{c}\text { (Papón) } \\
\text { (Centurión) }\end{array}$ & $\begin{array}{c}3 \\
\text { (Button) }\end{array}$ & $\begin{array}{c}4 \\
\text { (Lista) }\end{array}$ \\
\hline $\begin{array}{l}\text { Parajes poblados } \\
\text { entre montañas }\end{array}$ & $\mathrm{X}$ & $\mathrm{X}$ & $\mathrm{X}$ & $\mathrm{X}$ \\
$\begin{array}{l}\text { Lugar maravilloso } \\
\text { o con riquezas }\end{array}$ & $\mathrm{X}$ & - & $\mathrm{X}$ & - \\
$\begin{array}{l}\text { Presencia de } \\
\text { duendes y/o brujos }\end{array}$ & $\mathrm{X}$ & $\mathrm{X}$ & - & $\mathrm{X}$ \\
$\begin{array}{l}\text { Sucesos volcánicos } \\
\text { Grandes animales }\end{array}$ & $\mathrm{X}$ & - & - & - \\
Cultivos o plantíos & - & - & $\mathrm{X}$ & $\mathrm{X}$ \\
\hline
\end{tabular}

Así pues, se advierte que todos los relatos coinciden en situar los lugares habitados (ciudades o poblados) entre montañas, vale decir en la zona de la precordillera oriental, y, excepto la fuente 2, con más precisión en Última Esperanza. Que tales parajes fueran maravillosos (paraíso) o con riqueza (oro) es carácter compartido sólo por las fuentes 1 y 3 , en tanto que la presencia en ellos de duendes o brujos es una característica común en las relaciones de Papón, Centurión y Lista. La mención de sucesos volcánicos con testimonio de lavas es exclusiva de la primera fuente (Papón), aunque debe tenerse 
presente que está implícita en el párrafo siguiente al transcrito de Lista, en que este explorador explica las formaciones basálticas (volcánicas) de la sierra Baguales. La mención acerca de la presencia de grandes animales (cuadrúpedos) es compartida en los relatos de Button y Lista, y, por fin, la referencia a cultivos o plantíos es común para las fuentes 1 y 3. Es decir, hay entre estas cuatro relaciones, características parcialmente compartidas que sugieren un cierto parentesco conceptual con semejanza de origen, no obstante que distorsionado por la transmisión oral. En este respecto, cabe ponderar de manera diferenciada las fuentes, valorando las que proceden de Centurión y Lista como emanando directamente de los indígenas, en tanto que las correspondientes a Papón y Button han sido matizadas o relativizadas por los informantes que escribieron sobre ellas.

Abundando sobre lo expuesto y comentado, debe recordarse el atractivo evidente que ejercían sobre los aónikenk los parajes montañosos del pie de los Andes; basta recorrer la entretenida y minuciosa relación de viaje de Musters para comprenderlo. Es comprensible, así, que en tales lugares en tanto que diferentes del común estepario, con despliegue de formas geológicas y bloques pétreos con sugerencias misteriosas incomprensibles, y con abundancia de recursos, en fin, el imaginario indígena situara en ellos los escenarios de sucesos portentosos o las habitaciones de gualichos, duendes o seres humanos de apariencia extraña, como los chélep.

Tal pudo darse especialmente en el sector terminal oriental de la sierra Baguales. Desde luego está claro que los informantes de Lista dieron a entender sin duda que los indígenas habían cruzado por allí en vez de pasar por su periferia, único modo de comprender el ataque que habrían sufrido por parte de los cuadrúpedos monstruosos.

El lugar geográfico de que se trata no sólo llamó intensa y recurrentemente la atención de los aborígenes, sino también la de los foráneos que en diferente tiempo lo han conocido. Recordamos así la incursión del ingeniero alsaciano Hilaire Bouquet, en 1874, quien encontró en unas formaciones volcánicas una gruta que llamó "maravillosa" y que describió en detalle $e^{10}$. Más cerca en el tiempo, cabe citar el testimonio del botánico sueco Carl Skottsberg,

10 Véase nuestro artículo "Viajeros desconocidos en la Patagonia Austral durante la década de 1870" (Magallania, volumen 32, Punta Arenas, 2004). que cruzó por allí en 1908 en marcha desde el lago Argentino hacia Última Esperanza, quien advirtió que el paso en sí es muy pintoresco, sus enormes columnas y masas de piedra tienen la forma de ruinosos castillos y fuertes ${ }^{11}$. Dos décadas después, en febrero de 1929, el explorador P. Alberto De Agostini cruzó en sentido inverso, de sur a norte, y apreció un panorama geológico y orográfico semejante: En el trayecto se descubren paisajes nuevos y severos, ofrecidos por los austeros picos basálticos que asumen el aspecto de majestuosos castillos ornados de almenas y torres, o de largas crestas afiladas como cuchillos.

El valle en su parte final, serpentea entre estrechos desfiladeros donde los montes erguidos como gigantescos murallones se tornan negros y ásperos, demostrando con mayor evidencia la naturaleza volcánica de sus rocas ${ }^{12}$.

Si tales fueron los sentimientos de europeos cultos a la vista de las formas orográficas y geológicas, sugiriendo a sus mentes las imágenes de castillos y fortalezas, se comprende cómo, con mucha mayor razón, tales paisajes debieron impresionar fuertemente a los ignaros indígenas que pudieron ver en ellos verdaderas ciudades.

Aun en nuestro tiempo la gente común ha podido admirarse a la vista de esas expresiones sugerentes de la naturaleza patagónica. Recordamos, en efecto, cuanto nos contaban años atrás el señor Oscar Vidal Gómez, propietario de la estancia "La Cumbre", y su esposa Anita, acerca de sus impresiones respecto de lo visto en los altos valles de la sierra Baguales, escenas naturales de tanta sugerencia como para ver en ellas la obra de seres extraterrestres...

El volcanismo activo, con sus conos eruptivos más audibles que visibles, acompañado eventualmente por movimientos telúricos; y también el inerte, con sus formas de lava caracterizadoras visibles en distintos lugares de su vasto territorio, fue otra razón de temor supersticioso sobre la que abundan las menciones de exploradores y viajeros. En especial cabe recordar las referencias que dejaran el misionero Schmid (op. cit., págs. 64 y 145). Otra referencia se encuentra en otra relación anónima que diéramos

11 La Patagonia salvaje (Zagier \& Urruty Publications, Buenos Aires 2004, pág. 231.

12 Andes Patagónicos (Buenos Aires 1945, págs. 114 y 115). 
a conocer tiempo atrás, en la que el informante, citando a los jefes indígenas Huisel, Casimiro y otros, señala específicamente que las cordilleras terminan al sur del río Santa Cruz, i que se halla una Bahía en la última ramificación de esta con un Volcán a su izquierda que hace temblar la tierra de continuo ${ }^{13}$. Esta referencia podría corresponder a los volcanes Reclus o Burney, el primero de los cuales tiene documentada una grande y continuada actividad en épocas pasadas.

De tal modo, entonces, debe convenirse en que las características geográficas (orográficas, geomorfológicas y fisiográficas), geológicas y telúricas, que en impresionante despliegue combina y exhibe en diferentes lugares el territorio patagónico oriental, especialmente hacia su parte más occidental, despertaban el asombro de sus habitantes indígenas, podía llenarlos de temor o de admiración maravillada, según fueran los casos, que no acababan de entender racionalmente y, para una explicación satisfactoria, tal carencia o limitación era suplida mediante la fuerza creadora de su fantasía. Así, pasando de generación en generación, y eventualmente nutrido por sucesivas experiencias visuales pudo generarse, mantenerse, enriquecerse y renovarse el imaginario colectivo, parte preciada de su cultura.

La mención de Button sobre cultivos, como la de Papón sobre árboles frutales, nos recuerda las nociones más o menos vagas que los aónikenk pudieron tener sobre los pueblos patagónicos de más al norte, en concreto sobre aquellos que poblaban el gran distrito septentrional del lago Nahuelhuapi, entre la cordillera de los Andes y los ríos Neuquén y Limay, o sea, sobre los huilliches y pehuenches, quienes efectivamente eran sedentarios y como tales cultivaban maíz y criaban animales como ovejas, caballos y aun vacunos, además que en sus tierras crecían los manzanos, introducidos en lejana época desde Chile occidental por los misioneros jesuitas de Chiloé, y cuyos frutos eran utilizados en la alimentación indígena. Al respecto debe recordarse que dicha noción entre los indios aónikenk de fines del siglo XIX, sólo podía proceder de los recuerdos y dichos de los más viejos, que habían alcanzado

13 Véase nuestro artículo "Documentos inéditos para la Historia de Magallanes (I Bosquejo sobre la Historia Natural de Magallanes i las costumbres de sus habitantes)" (Anales del Instituto de la Patagonia, Serie Ciencias Humanas, vol. 29, Punta Arenas 2001), pág. 217. en sus trashumancias ocasionales hasta aquellos lugares septentrionales tan lejanos, posibilidad que sabemos quedó abruptamente cortada para los más jóvenes luego de la llamada "Conquista del Desierto" (1879-1883) por las tropas argentinas al mando del general Julio A. Roca y otros jefes. Así, cualquier noción sobre el punto para la época de que se trata debió probablemente emanar de la tradición indígena. El documento denominado "Memorando", esto es la quinta fuente, de carácter complementario solamente en lo que interesa, entrega una referencia específica.

A la luz de estos antecedentes, aunque imprecisos y en parte confusos, hecho explicable por la intervención de tantos agentes transmisores, cabe reflexionar acerca de cuán rico hubo de ser el acervo imaginario de los aónikenk, del que apenas una fracción mínima llega al conocimiento académico a través de esta comunicación. Extinguidos para siempre los antiguos cazadores-recolectores del sur de la Patagonia, está visto que la única fuente que permitiría obtener mayor información sobre la materia está en el hallazgo de nueva documentación inédita -tal y como ha venido ocurriendo en años recientes y sobre los que esta revista ha dado cuenta-, que, debidamente ponderada y considerada, permita profundizar en el arcano del imaginario indígena y comprender así, mejor, lo que fuera su mundo espiritual y su cultura.

\section{CONCLUSIÓN}

El contenido de la primera de las fuentes revisadas (la atribuida a Papón), en tanto que la noticia esencial que contiene se refiere a una ciudad entre montañas, con carácter de extraordinaria, trae de inmediato a la memoria el mito de la Ciudad Encantada de la Patagonia o de los Césares. Pero, bien considerada la información, en cuanto la misma se completa con el hecho de que esa población singular habría sido sepultada por las lavas de erupciones volcánicas, se advierte que la relación entre una y otra ciudades no pasa de la mera apariencia. En efecto, falta en la información indígena una cualidad que es indispensable en el mito cesáreo, esto es, la de la permanencia en el tiempo de la Ciudad Encantada. Esto, a nuestro juicio, basta para desechar los antecedentes de que se ha dado cuenta, en especial de los que se atribuyen a la información 
originada en el jefe Papón, como una nueva fuente de la leyenda de los Césares.

De manera que, y ya en la apreciación totalizadora del conjunto de antecedentes colacionados, procede formular como hipótesis explicativa la de encontrarnos con más de una, posiblemente con dos variantes, de una fantasía generada desde largo tiempo por el imaginario colectivo aónikenk. Las mismas se refieren a sendas creaciones referidas a la existencia en uno o más sectores de la precordillera oriental de una población entre montañas habitada por seres maléficos, primera vertiente; o un paraje igualmente poblado y abundante en riqueza y en bienestar para sus habitantes, que consideramos como una segunda variante. De ambas, la primera parece más consistente con otras informaciones recogidas por la etnohistoria, que hacían habitar a los duendes y gualichos por diferentes lugares, asociados generalmente con paisajes de carácter volcánico. No obstante ello, la idea de una población misteriosa, siniestra o no, ubicada entre montañas, nos parece que conforma la esencia de lo recogido y valorizado de las diferentes fuentes. Todo ello, es claro, en el amplio contexto de una explicación satisfactoria de los áonikenk para el mejor entendimiento de su vasto ambiente natural, en su rica variedad paisajística y fisiográfica.

Hay, pues, con lo expuesto, materia suficiente para mantener vigente el interés de los etnohistoriadores.

\section{FUENTES DE CONSULTA}

AgOSTINI, AlBERTO M. DE. 1945. Andes Patagónicos. Buenos Aires.

AINSA, FERNANDO. 1989. Una utopía necesaria: la Ciudad de los Césares. La Nación, ediciones del 15 y 22 de enero. Buenos Aires.

ANGELIS, P. D. 2005. La Ciudad Encantada de la Patagonia. La Leyenda de los Césares. Ediciones Continente, Buenos Aires.
ARRIAGADA, RAMÓN. 2006. Arthur Button: un sorprendente hallazgo. Actas V Congreso de Historia de Magallanes. Ediciones de la Universidad de Magallanes. Punta Arenas.

COUYOUDMJIAN, RICARDO. 1971. La leyenda de los Césares. Historia 10: 76-107. Santiago.

C.S.O. 1929. Historia de una historia. El Magallanes ediciones del 22 de febrero y del 7 de marzo. Punta Arenas.

ESTELLÉ, PATRICIO y RICARDO COUYOUDMJIAN. 1968. La Ciudad de los Césares: origen y evolución de una leyenda (1526-1880). Historia 7: 283-309. Santiago.

LISTA, RAMÓN. 1896. Viaje a los Andes Australes. Anales de la Sociedad Científica Argentina, tomo XLI. Buenos Aires.

MARTINIC B., MATEO. 1992 (2006). Historia de la Región Magallánica. Ediciones de la Universidad de Magallanes. 2000. Informaciones etnográficas extraídas del diario inédito de Santiago Dunne, secretario de la Gobernación de Magallanes (1845). Anales del Instituto de la Patagonia, Serie Ciencias Humanas, 28:45-52. Punta Arenas.

2001. Documentos inéditos para la Historia de Magallanes. Anales del Instituto de la Patagonia, Serie Ciencias Humanas, 29: 211-238. Punta Arenas.

2004. Viajeros desconocidos en la Patagonia Austral durante la década de 1870. Magallania 32: 5-13. Punta Arenas.

2005. De la Trapananda al Áysen. Pehuen Editores. Santiago.

2007. Documentos inéditos para la Historia de Magallanes. "Memorando sobre los Patagones". Magallania, 35 N$^{\circ} 2$ : 159-164. Punta Arenas.

SKOTTSBERG, CARL. 2004. La Patagonia salvaje. Zagier \& Urruty Publications. Buenos Aires.

VEGA DELGADO, CARLOS y CARLOS VEGA CACABELOS. 2006. Develando el misterio de la Ciudad de los Césares. Fondo Nacional de la Cultura y de las Artes. Punta Arenas. 